\title{
First two-way laser ranging to a lunar orbiter: infrared observations from the Grasse station to LRO's retro-reflector array
}

\author{
Erwan Mazarico ${ }^{1 *} \mathbb{D}$, Xiaoli Sun ${ }^{1}$, Jean-Marie Torre ${ }^{2}$, Clément Courde², Julien Chabé2 ${ }^{2}$ Mourad Aimar², \\ Hervé Mariey², Nicolas Maurice², Michael K. Barker', Dandan Mao 1,3, Daniel R. Cremons', Sébastien Bouquillon4, \\ Teddy Carlucci ${ }^{4}$, Vishnu Viswanathan ${ }^{1,5}$, Frank G. Lemoine ${ }^{1}$, Adrien Bourgoin ${ }^{6}$, Pierre Exertier ${ }^{7}$, \\ Gregory A. Neumann', Maria T. Zuber ${ }^{8}$ and David E. Smith ${ }^{8}$
}

\begin{abstract}
We present the results of the first series of successful two-way laser ranging experiments from a ground station, the Lunar Laser Ranging (LLR) station in Grasse, France, to a spacecraft at lunar distance, the Lunar Reconnaissance Orbiter (LRO). A $15 \times 18 \times 5 \mathrm{~cm}, 650$-g array of twelve 32-mm diameter solid corner cubes is mounted on its anti-nadir deck. Ranging to this small retro-reflector array onboard a lunar orbiter from a ground station was a challenge compared to ranging to larger lunar surface retro-reflectors. Grasse measured 67 returns in two 6-min sessions on September 4, 2018. Clear returns were also recorded during two additional sessions on August 23-24, 2019 for which active slewing by LRO was performed to bring the array in view of the station. The measured echos yielded range residuals less than $3 \mathrm{~cm}$ (two-way time-of-flight RMS $<180 \mathrm{ps}$ ) relative to the reconstructed LRO trajectory. This experiment provides a new method of verifying theories of dust accumulation over decades on the lunar surface. It also showed that the use of similar arrays onboard future lunar landers and orbiters can support LLR lunar science goals, particularly with landing sites near the lunar limbs and poles, which would have better sensitivity to lunar orientation.
\end{abstract}

Keywords: Laser ranging, Orbit determination, Moon, Data reduction techniques

\section{Introduction}

For 50 years, Lunar Laser Ranging to surface laser retroreflector arrays (LRAs) by lasers at Earth stations has provided important geodetic data constraining the lunar ephemeris and orientation, with implications for both lunar interior properties and for astrophysics and fundamental physics.

Technological improvements to the station equipments, such as detectors, lasers, and telescopes, have improved the accuracy of the ranging measurements from tens of centimeters to sub-cm (Murphy 2013; Courde et al. 2017b; Müller et al. 2019). Since 2008,

\footnotetext{
*Correspondence: Erwan.Mazarico@nasa.gov

${ }^{1}$ NASA Goddard Space Flight Center (GSFC), Greenbelt, MD, USA Full list of author information is available at the end of the article
}

robotic missions from NASA and other nations have brought a wealth of new scientific data and pushed lunar science further. The recent support for commercial robotic exploration and for landed human exploration has given new opportunities for LLR. NASA Goddard Space Flight Center (GSFC) has developed a set of miniature LRAs to be mounted on future lunar landers (Sun et al. 2019) for ranging by orbiting laser altimeters or rangefinders. Larger single retro-reflectors are being developed (Currie et al. 2011; Dell'Agnello et al. 2014) for ranging directly from Earth expanding the LLR dataset's geometric strength.

Here, we report on a two-way laser ranging experiment at lunar distance much akin to LLR except the target is a small retro-reflector array onboard the Lunar Reconnaissance Orbiter (LRO) spacecraft, $<1 / 10$ th the area of 
the Apollo 11 array and 1/30th the mass if counting the support structure. The primary science objective is to provide baseline measurements to a new and pristine retro-reflector array at the lunar distance, as it was proposed that lunar dust had accumulated on the Apollo and Lunokhod retro-reflectors on the lunar surface over decades and reduced their reflectivity (Murphy et al. 2010, 2014). As LLR is the only long-lived instrument on the lunar surface, understanding the potential degradation of the signal is important. Moreover, the possible systematic effects, that would result from dust-driven thermal effects for instance, may impact the data analysis, with implications across very diverse fields from fundamental physics to geophysics.

The LRO LRA is the first on a spacecraft at lunar distance to have been successfully ranged from Earth. More recently, the relay satellite Queqiao for the Chang'E 4 mission launched and included a 100-mm hollow corner cube in its payload (He et al. 2018). It was placed in a halo orbit around the Earth-Moon Lagrangian point L2, 450,000 km from Earth, to provide farside coverage.

In the first few years of the LRO mission, during the one-way Laser Ranging (LR) campaign (Zuber et al. 2010; Mao et al. 2017), a number of attempts were made to range to the LRO LRA from the Apache Point station (APOLLO) (Murphy et al. 2008), but these were not successful due to a number of factors, including weather, operational issues, and spacecraft geometry constraints. One major issue was the narrow range gate of the APOLLO detector $(\sim 100 \mathrm{~ns})$ relative to the uncertainty in the spacecraft trajectory prediction, less accurate early in the LRO mission before the GRAIL gravity fields were available (Zuber et al. 2013). In 2018, a renewed effort with the Grasse LLR station in France was initiated. Grasse is capable of laser ranging at $1064 \mathrm{~nm}$ wavelength with single photon detection, which has been proven to be more advantageous than $532 \mathrm{~nm}$ (Courde et al. 2017b; Chabé et al. 2020) (see the "The Grasse laser ranging station" section). The GRAIL-derived gravity fields also enabled improved orbit determination and thereby reduced the orbit prediction errors. Several successful two-way laser ranging observation sessions were made from the Grasse station, but not enough at this time to robustly assess the link margin to the LRO array and thus quantify the relative loss of the surface arrays from dust accumulation over 5 decades. This manuscript is thus focused on documenting the experiment and its first successes, as we are continuing to plan and execute more observation sessions.

Beyond their use to assess the relative return strength of the surface reflectors, 2-way laser ranging observations to LRO could provide geodetic range information on the LRO trajectory. However, at this time, with only a few successful passes spread over a year, they are too sparse to be able to support orbit determination efforts. This may be possible in the future with great operational effort, but is not explored further here. Concurrent 1-way and 2-way laser ranging to LRO may be achievable in the future, which would provide a way to synchronize absolutely the spacecraft clock to ground stations. This would also allow stations to synchronize their time, much like the 'Time Transfer by Laser Link' (T2L2) experiment (Exertier et al. 2010, 2013). While the relatively low altitude $(\sim 1300 \mathrm{~km})$ of the T2L2 space platform did not allow distant stations to range simultaneously, a target at lunar distance like LRO with its retro-reflector array and Laser Ranging telescope would allow multiple stations spread over a whole hemisphere to be synchronized at once.

In the "Description of the experiment" section, we describe the experiment, the flight and ground segments, and the observation constraints. In the "Two-way laser ranging observations" section, we detail the geometry of the four successful sessions where two-way returns could be clearly identified. In the "Analysis" section, we present the analysis of the raw distance measurements and evaluate their quality, and compare them in the "Discussion and perspectives" section to those typical of surface retro-reflectors.

\section{Description of the experiment}

The LRO retro-reflector array

The LRO LRA was designed by KBRwyle (then ITE Inc.) for NASA GSFC. It consists of twelve 32-mm diameter solid corner cube retro-reflectors in a $4 \times 3$ array pattern. Its dimensions are $15 \times 18 \times 5 \mathrm{~cm}$.

The array was mounted on the spacecraft- $\mathrm{Z}$ panel (the Avionic Radiator). A low thermal conductivity spacer reduces the thermal fluctuations and gradients of the LRA due to spacecraft temperature variations. The LRA was tested from $-160{ }^{\circ} \mathrm{C}$ to $+30{ }^{\circ} \mathrm{C}$ for 8 cycles during the LRO thermal vacuum testing. It was physically located near the foot of the High-Gain Antenna (HGA) boom (Fig. 1), and it is typically oriented opposite to the lunar surface (the nadir direction). The center of the array at the base in the spacecraft coordinate system is [341.6, -716.7, -697.7] $\mathrm{mm}$ along the $\mathrm{X}, \mathrm{Y}$, and $\mathrm{Z}$ directions, respectively. The vertices of the retro-reflectors are $19.1 \mathrm{~mm}$ above the base.

The corner cubes are made of Suprasil (quartz), and they have a $90^{\circ}$ dihedral angle (unspoiled) with 0.3 arcsec tolerance. The retro-reflectors were mechanically constrained in an aluminum holder. They are spring-loaded into their mounts on an aluminum baseplate covered with IPO silver-coated Kapton tape. Figure 1 shows pictures of the LRA mounted on LRO. Their top surface 

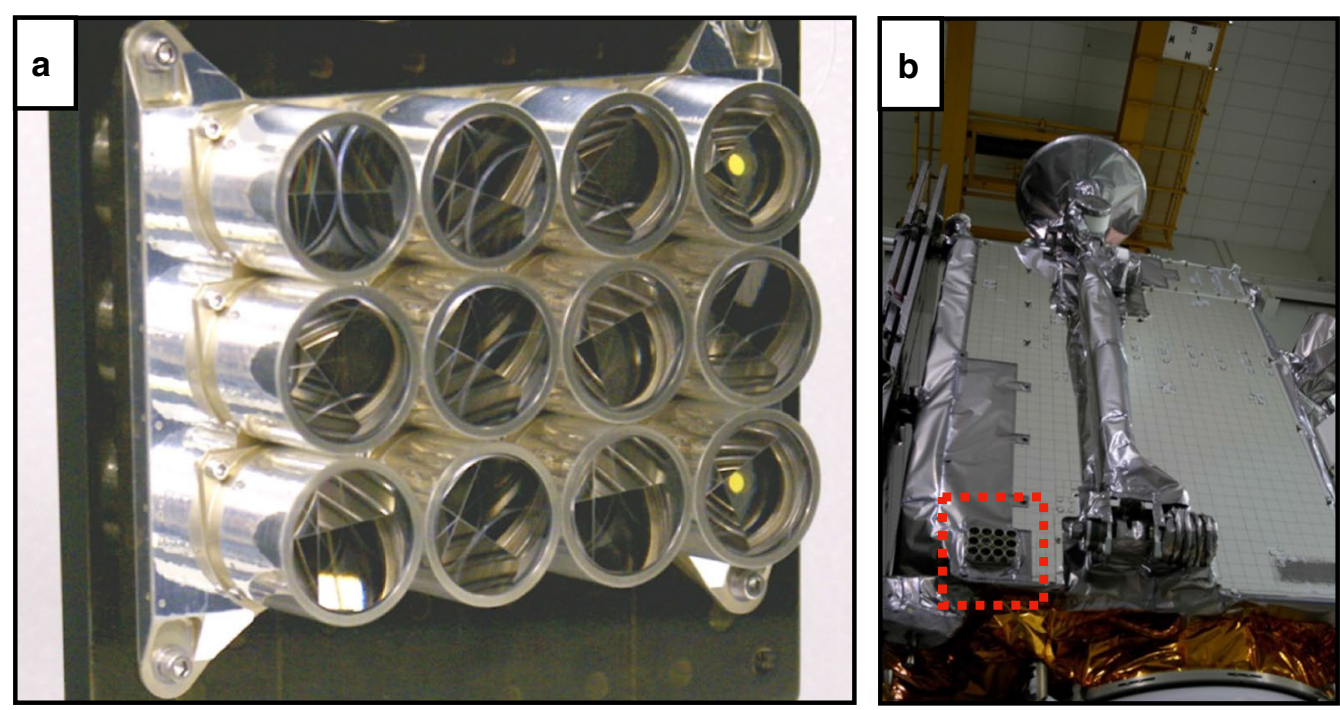

Fig. 1 Photographs of the LRA mounted on the LRO spacecraft. a Close-up view. b Context view of the anti-nadir deck. The large arm holding the $\mathrm{HGA}$ is visible in its stowed configuration

has a broadband Anti-Reflection coating. They are Total Internal Reflection (TIR) cubes, meaning their back surfaces are uncoated. This was deemed preferable to coated cubes given the LLR experience of Apache Point (Murphy et al. 2008) with reduced returns from Lunokhod 2 when it was sunlit. Unlike the Apollo cubes, the Lunokhod cubes are silver-coated. The temperature gradient along the optical axis of the cubes under the Sun is much greater than that of uncoated cubes. The aluminum or silver coating on the back of cubes absorbs more infrared radiation, which results in internal thermal gradients and can lead to phase distortions or loss of perpendicularity between the faces that affect the far-field diffraction pattern. In contrast, the infrared radiation passes through the TIR cubes with little absorption. Therefore, and despite the reduced cross-section in comparison to coated cubes, the TIR approach was chosen for the LRO LRA to promote experimental success.

Prior to spacecraft integration, the LRA was tested optically with a $2.72-\mathrm{m}$ focal length collimator at $532 \mathrm{~nm}$ and a CCD at the focal plane with $7.4 \mu \mathrm{m}$ square pixels $(2.73 \mu \mathrm{rad} /$ pixel). Figure 2 shows the far-field pattern of a single corner cube as well as the whole array at a normal incidence angle. The size of the primary lobe in the far-field pattern was measured at $41.95 \mu \mathrm{rad}$, close to the theoretical prediction of $40.95 \mu \mathrm{rad}(2.44 \times N$ diameter $)$. The extinction angle, at which little to no light is reflected back, is $\sim 20^{\circ}$ (not shown).

This LRA was made more than 10 years ago when all LLR stations operated at $532 \mathrm{~nm}$ where detectors were most sensitive. Recently, however, the Grasse

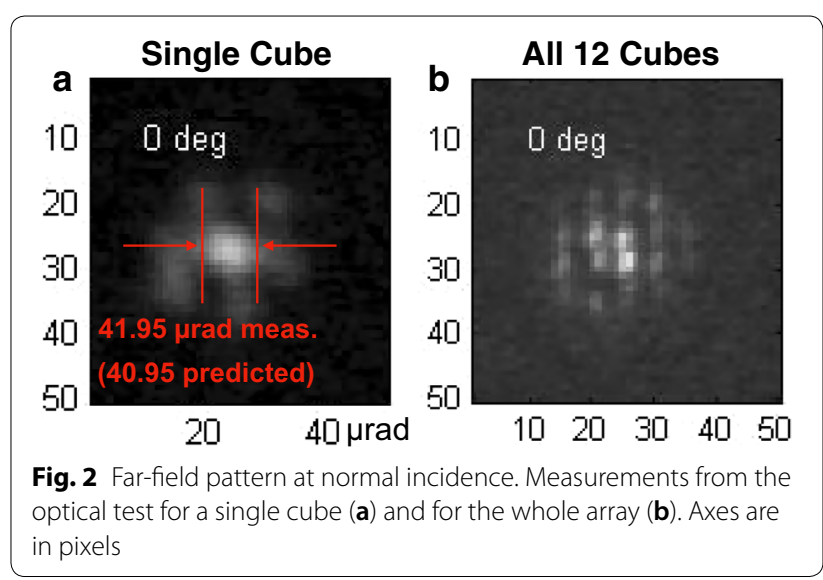

station has successfully ranged to the surface reflectors at $1064 \mathrm{~nm}$, a wavelength that offers several advantages [see "The Grasse laser ranging station" section, also (Courde et al. 2017b)]. We conducted a set of new measurements of the optical cross-section (OCS) of a single retro-reflector, a flight spare for the array onboard LRO. The test setup is shown in Fig. 3. The new test setup included a $2.5-\mathrm{m}$ focal length collimator operating consecutively at $532 \mathrm{~nm}$ and $1064 \mathrm{~nm}$. The CMOS camera at the focal plane recorded far-field patterns at $2048 \times 2048$ pixels $(2.15 \mu \mathrm{rad} / \mathrm{pixel})$. The intensity of each pattern was calibrated using a same-size protective silver-coated mirror with known reflectance. The experimental settings were held constant between measurements of the corner cube and the reference 

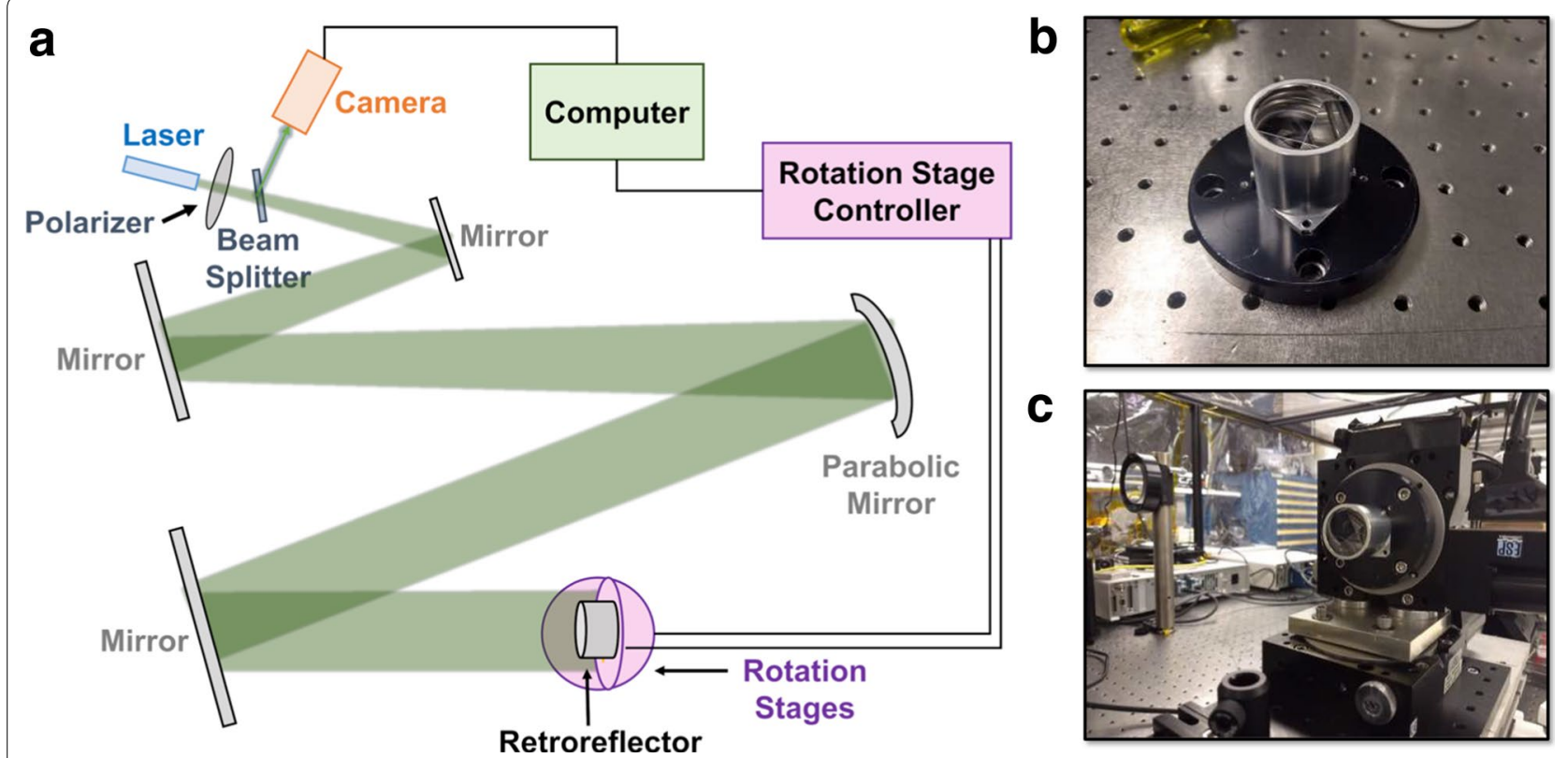

Fig. 3 Optical test setup. a Schematic representation of the LRA cross-section measurement setup at both $532 \mathrm{~nm}$ and $1064 \mathrm{~nm}$ in 2019 . b View of the LRO corner cube flight spare. $\mathbf{c}$ View of the RR and rotation stages on the optical test bench

mirror. The results, both at 532 and $1064 \mathrm{~nm}$, are presented in Fig. 4a, b, which shows that the cross-section is significantly more favorable at $532 \mathrm{~nm}$ (by a factor of $\sim 7$ ) due to narrower beam divergence at shorter wavelengths per diffraction theory. The cross-section decreases gradually up to $\sim 25^{\circ}$ (this value is dependent on the laser axis of polarization with respect to the corner cube orientation).
The LRO LRA has a total mass of $650 \mathrm{~g}$ and measures $15 \times 18 \times 5 \mathrm{~cm}$. It was tested to the $\mathrm{LRO}$ operational environment $\left(-150^{\circ} \mathrm{C}\right.$ to $\left.+30{ }^{\circ} \mathrm{C}\right)$ prior to mounting on LRO, and thermally isolated from the spacecraft. It was tested to 14-g vibration levels.

The LRO LRA was added to the $-\mathrm{Z}$ deck of the spacecraft mid-way in the LRO development and used a set of existing mounting screw holes at the foot of the HGA. As
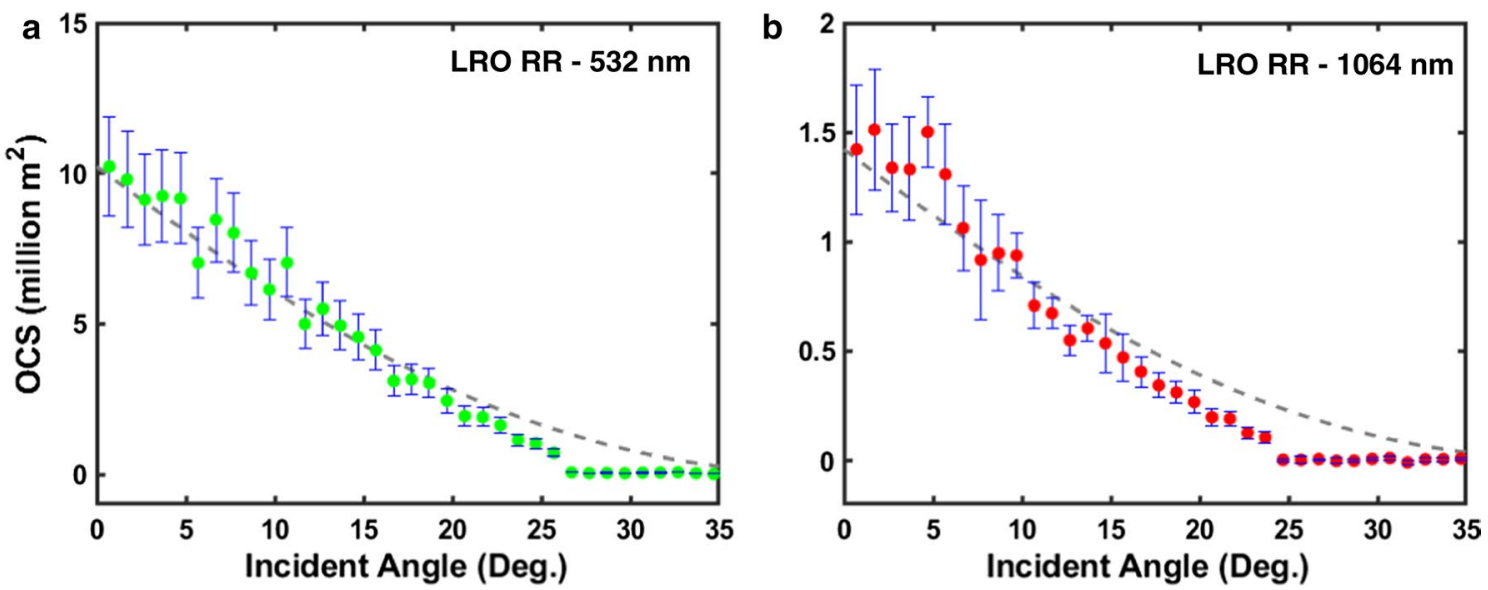

Fig. 4 New optical test results. Measurements of the peak optical cross-sections (OCS) at 532 (left column) and $1064 \mathrm{~nm}$ (right column) of a RR flight spare of the LRO LRA. Five far-field diffraction patterns were averaged for the entire range of the incidence angles tested; the error bars indicate one standard deviation. The gray line indicates the theoretical prediction based on the reduction of the cross-sectional area (Minott 1974). The OCS measurements at each wavelength were calibrated against a 1.25-in. silver mirror 
a result, the close proximity to the base of the HGA boom can partially obstruct incoming laser pulses and thus limit ranging opportunities. Ranging to the LRA does not necessarily require spacecraft maneuvers. These operationally passive attempts require very specific geometry. More opportunities can be found if the spacecraft slews to bring the array in view of the ground station; however, these active attempts require advance coordination to execute specific slews, and they are still subject to numerous constraints. The HGA is primarily pointed in the $-\mathrm{Z}$ direction when $\mathrm{LRO}$ is close to the equator (as is the case in passive attempts) and is fixed in that direction when large slews are executed for our active attempts. As shown in Fig. 5, we therefore select observation opportunities that place the Earth within only half of the field of view (180-360 azimuth range, green in the figure).

\section{The Grasse laser ranging station}

The Grasse laser ranging station is located on the Calern plateau, $20 \mathrm{~km}$ from the city of Grasse (French Riviera). This $20 \mathrm{~km}^{2}$ semi-desertic karstic plateau at $1320 \mathrm{~m}$ elevation has a high number of clear nights and a circulation of marine winds in horizontal layers that result in a stably stratified atmosphere. Since the 1980s, the Grasse laser ranging station has been the most significant contributor to LLR observations, and it is part of the International Laser Ranging Service (ILRS) (Pearlman et al. 2019).

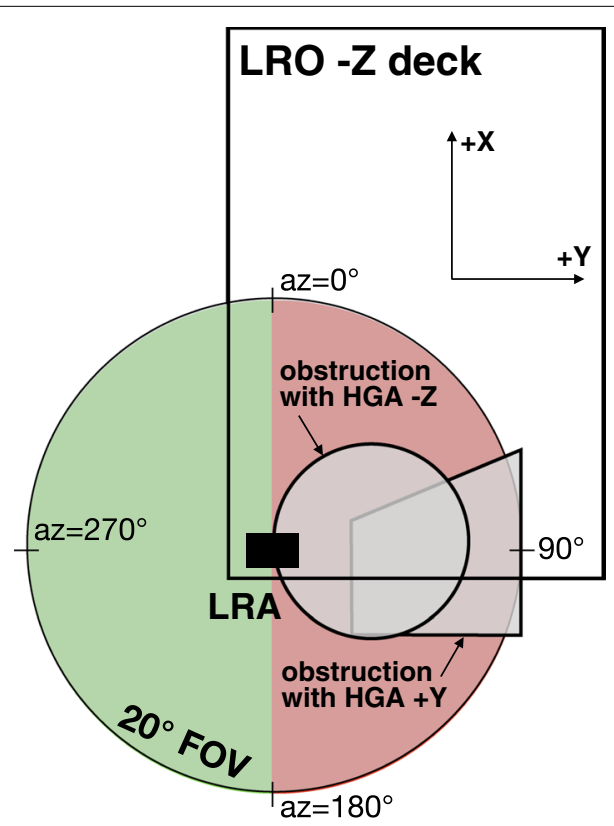

Fig. 5 Location of $L R A$ on the $L R O-Z$ deck. Partial obstruction occurs due to the HGA and HGA boom. The green half-disk shows the preferred region for the Earth station when conducting two-way laser ranging
The collection of LLR data is part of a regular long-term observing program (Courde et al. 2017b; Müller et al. 2019). The LLR data are available at the data centers of the ILRS, including the NASA Crustal Dynamics Data Information System (CDDIS) (Noll 2018).

The station employs a 1.54-m Alt-Az Ritchey-Chrétien design telescope with direct drive motorization that also makes it suitable for low Earth orbit Satellite Laser Ranging. The laser is a neodymium-doped yttrium aluminum garnet (Nd:YAG) laser emitting in the infrared at a wavelength of $1064 \mathrm{~nm}$. The second harmonic generation frequency-doubling method is used to obtain a wavelength of $532 \mathrm{~nm}$ so that the energy per pulse, available for ranging, is $0.15 \mathrm{~J}$ at $532 \mathrm{~nm}$ (green) and $0.30 \mathrm{~J}$ at $1064 \mathrm{~nm}$ (infrared).

The time base of the station is delivered by a T4 Science $\mathrm{H}$-maser clock with a frequency stability better than $10^{-12}$ at $1 \mathrm{~s}$. The time tagging of the emitted and received photons is done by a Dassault event timer. Since 2017, Grasse uses the $1064 \mathrm{~nm}$ wavelength of the Nd:YAG laser for LLR (Courde et al. 2017b) with an InGaAs/InP single-photon avalanche diode (SPAD) as a detector. The Grasse station has demonstrated that performing LLR in the infrared increases the return photon rate by a factor of 8 during the new and full Moon periods and thus improves the temporal homogeneity of LLR observations over a synodic month. There are several reasons that explain the experimental observation of increased link budget in LLR using infrared wavelength. First, by removing the frequency-doubling system of the Nd:YAG laser, the number of photons is improved by a factor of 3. Second, there is a better atmospheric transmission in the infrared; for example in a clear atmosphere, the transmission is improved by a factor 1.9 at $20^{\circ}$ elevation angle and by 1.32 at $40^{\circ}$ (Degnan 2013). Third, the far-field pattern from a corner cube reflector in the infrared is less affected by the atmosphere even though the size of the diffracted beam is larger than in the green. Taking into account a typical $5 \mu \mathrm{rad}$ velocity aberration, the relative gain in intensity between $1064 \mathrm{~nm}$ and $532 \mathrm{~nm}$ is 1.3 on Apollo arrays and 2.1 on Lunokhod arrays (Courde et al. 2017a). In addition, because of the transmittance and the scattering effects in the atmosphere, the solar background photons are much reduced at $1064 \mathrm{~nm}$ compared to $532 \mathrm{~nm}$ for elevation angles greater than $30^{\circ}$. All of these properties increase the signal to noise ratio and extend the ability of the Grasse LLR station to range the lunar retro-reflectors at lower elevation angle and closer to new and full Moon (lunar phases with a general lack of LLR data).

The Lunar Orbiter Laser Altimeter (LOLA) onboard LRO has five detectors capable of precisely time tagging laser pulses, to measure the round-trip light time and 
thus the range from the spacecraft to the surface (Smith et al. 2009). One of the five LOLA detectors is capable of receiving green laser pulses from Earth stations through the Laser Ranging Telescope (LRT) mounted on the LRO HGA, enabling one-way Laser Ranging (Zuber et al. 2010) at a much lower laser power from Earth stations. For one-way laser ranging, the maximum allowed 532-nm pulse energy for the ground stations is $1 \mathrm{fJ} / \mathrm{cm}^{2}$ at LRO for $<100$ ps laser pulses. Thus, the laser power at Grasse had to be attenuated by 2-3 orders of magnitude during one-way laser ranging and the $532 \mathrm{~nm}$ output switched off and $1064 \mathrm{~nm}$ only used, at full power, during 2 -way laser ranging.

The Grasse station performed an early series of oneway ranging at $532 \mathrm{~nm}$ at a reduced laser power to verify the pointing of the telescope and the validity of the predictions. For two-way ranging to LRO, the laser was used at $1064 \mathrm{~nm}$ in a burst mode: firing three laser pulses in succession, separated by $7.150 \mathrm{~ns}$ at $10 \mathrm{~Hz}$ repetition rate. This 3-pulse pattern maximizes the useful laser energy transmitted by the laser and improves the return probability. The $7.15 \mathrm{~ns}$ separation between pulses is fixed and related to the size of the laser cavity.

The local meteorological and atmospheric turbulence parameters during the successful LRO two-way laser ranging sessions (passes) are listed in Table 1. The atmospheric turbulence parameters are measured by a Generalized Differential IMage Monitor (G-DIMM) at the Calern Observatory (Aristidi et al. 2019). The relatively high humidity (92\%) on the second successful pass is due to clouds at the height of the station.

\section{Observation geometry}

The observation geometry is similar to the case of the LLR measurements to retro-reflectors on the lunar surface. The fact that the LRO LRA is in lunar orbit is not in itself a technological challenge as the ranging distance is essentially the same. However, there is additional complexity in several experimental aspects, which makes this experiment a significant technical challenge.

First, given the lunar orbit and orientation are now both very well known, the LLR prediction error in the expected two-way light times to the retro-reflectors on lunar surface is at the cm-level. Thus, the range gate for LLR observations can be kept very short in duration ( $\pm 50 \mathrm{~ns}$ ) which improves the detection probability by the Geiger-mode photon counters and even allows daytime observations. The LRO orbit prediction error available daily from the flight dynamics team is typically larger, typically a few tens of meters in total position and several meters in the line-of-sight, and can be worse if the predictions are stale, typically on weekends. For this reason (see Fig. 6), range gate predictions for the station are created from the latest available daily orbit prediction. Because most of this prediction error is in the along-track and cross-track directions, the LRO-Grasse line-of-sight distance prediction errors are actually smaller, up to $\sim 5$ $\mathrm{m}(1-\sigma) 1$ day out and up to $\sim 20 \mathrm{~m} 2$ days out (Table 2 ). A range gate, up to $\pm 150 \mathrm{~ns}( \pm 45 \mathrm{~m})$, was applied to take into account of this uncertainty. We note that in the four successful passes the phasing of the primarily once-perrevolution orbit error led to even smaller actual prediction errors.

Second, the phasing of the LRO orbit with respect of Earth seasons and the lunar orbit limits the number and duration of the 'passive' attempts. This is illustrated in Fig. 7 where each geometrical constraint is not drastic in itself given it only limits observations to $16-72 \%$ of the time, but in combination is only satisfied $\sim 0.6 \%$ of the time. Other factors, such as conflict with other instrument and spacecraft activities, position of the Earth and possible obstruction by the HGA or HGA boom, are not accounted for here, and would in reality further limit the number of possible passive attempts.

For this reason, more recently, we designed a number of LRO single-axis roll slews to align the $-\mathrm{Z}$ deck toward the Earth. This could increase the duration of the passes (from 5-10 min up to $40 \mathrm{~min}$ ) and open up additional orbits for ranging opportunity periods. However, this cannot substantially increase the number of opportunities. Slews can be precluded by other spacecraft activity and may not be possible if certain spacecraft rules cannot be followed (e.g., no occultation of the star trackers, power/thermal budget). Also, because of the relatively wide range gate, the detector can be overwhelmed by solar background photons, so LRO could not be observed

Table 1 Meteorological and atmospheric turbulence parameters during the successful LRO passes

\begin{tabular}{lllllll}
\hline Date (UTC) & Temp. $\left({ }^{\circ} \mathrm{C}\right)$ & Humid. $(\%)$ & Wind & Seeing & Isoplanatism & $\begin{array}{c}\text { Scintillation } \\
\text { index }\end{array}$ \\
\hline 2018/09/04 01:34 & 13 & 69 & $\mathrm{~N} / \mathrm{A}$ & $2.0^{\prime \prime}$ & $1.5^{\prime \prime}$ & $3.2 \%$ \\
2018/09/04 03:28 & 11 & 92 & $\mathrm{~N} / \mathrm{A}$ & $2.0^{\prime \prime}$ & $1.5^{\prime \prime}$ & $3.2 \%$ \\
$2019 / 08 / 2302: 34$ & 16.5 & 67 & $3.7 \mathrm{~m} / \mathrm{s}$ & $0.8^{\prime \prime}$ & $1.5^{\prime \prime}$ & $3.3 \%$ \\
$2019 / 08 / 2401: 56$ & 16.0 & 71 & $4.1 \mathrm{~m} / \mathrm{s}$ & $\mathrm{N} / \mathrm{A}$ & $\mathrm{N} / \mathrm{A}$ & $\mathrm{N} / \mathrm{A}$ \\
\hline
\end{tabular}



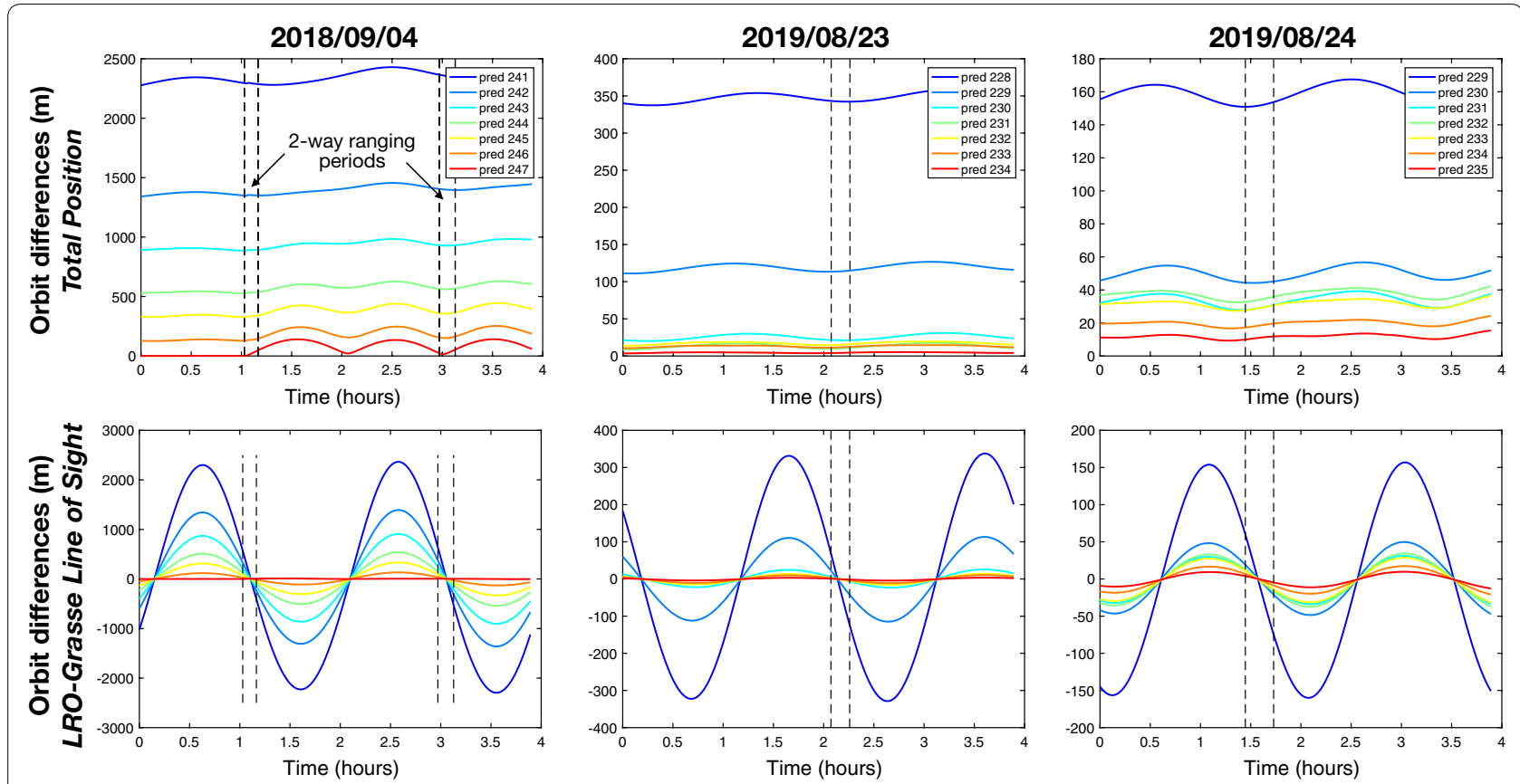

Fig. 6 Evolution of errors of daily orbit prediction project deliveries. These were assessed as the difference with the reconstructed orbit. Total position (dominated by the along-track component) and Grasse-LRO line-of-sight (LoS) discrepancies are shown. The periods where the two-way laser ranging was performed are indicated with vertical dashed black lines

against a bright Moon, limiting opportunities to local nighttime and face-on orbits.

\section{Two-way laser ranging observations \\ Setup}

In the beginning of this experiment, orbits that offered real-time one-way Laser Ranging opportunities were preferred to be able to correct orbit errors and verify the telescope pointing. The goal was to range to $\mathrm{LRO}$ with co-boresighted low pulse energies at $532 \mathrm{~nm}$ wavelength to be detected by LOLA's Detector 1 through the LRO LR telescope without the constraint in range gate, before the geometry allowed two-way ranging. Indeed, with passive attempts, returns were only possible when LRO was near the lunar equator $\left( \pm 20^{\circ}\right)$, so there were $\sim 10$ - $\mathrm{min}$ segments before and after these when LRO was still flying over the nearside. However, real-time radio contacts from the USN or DSN were needed to have near realtime feedback. Given the LRO tracking schedule was not firmly known in advance, when opportunity planning between GSFC and Grasse was occurring, this led to the cancelation of a number of attempts.

Careful evaluation of the orbit prediction errors in the Grasse-LRO line-of-sight direction and regular one-way Laser Ranging by the Grasse station to LRO, conducted before the two-way opportunities, gave confidence that 1064-nm attempts with no preliminary 532-nm LR were possible. High-quality orbit predictions were also sometimes produced with GEODYN using the high-accuracy modeling used in orbit reconstruction (Mazarico et al. 2018), but the daily predictions supplied by the LRO project were generally sufficient.

Orbit predictions were provided for the observation days in the SPICE SPK format to the Paris Observatory, which produced Grasse-specific light time and azimuth/ elevation prediction files in the 'Topocentric Prediction Format' (TPF), accounting for the latest Earth Orientation Parameters provided by the International Earth Rotation Service (IERS). Surrounding the LRO twoway sessions, the Grasse station conducted regular LLR observations of the surface LRAs, to verify pointing and to allow comparison of the return rates.

\section{Successful two-way session in September 2018}

The first successful two-way ranging occurred on September 4, 2018 during passive opportunities. The first success was during the second attempt period that night, between 01:31 and 01:40 UTC. The following pass between 03:28 and 03:38 UTC also yielded echos. Regular LLR to the Apollo 14 LRA was conducted prior and after the passes to provide a known baseline.

Figure $8 \mathrm{a}, \mathrm{b}$ shows the path of the Earth in the LRO spacecraft frame, within the LRA FOV and outside of the HGA obstruction zone. The incidence angle of each 
Table 2 RMS of orbit differences between predictions and reconstruction in total position and along the line-ofsight between Grasse and LRO. Orbit predictions and time periods are the same as in Fig. 6

\begin{tabular}{|c|c|c|c|c|}
\hline \multirow{2}{*}{$\begin{array}{l}\text { Prediction } \\
\text { Day of year }\end{array}$} & \multicolumn{2}{|c|}{ RMS difference $(m)$ in } & \multicolumn{2}{|c|}{ RMS difference $(m)$ in } \\
\hline & $\begin{array}{l}\text { Total } \\
\text { position }\end{array}$ & $\begin{array}{l}\text { Line-of- } \\
\text { sight }\end{array}$ & $\begin{array}{l}\text { Total } \\
\text { position }\end{array}$ & \\
\hline DOY) & Over 20 & & Over ran & periods \\
\hline
\end{tabular}

For observations on 2018/09/04 (DOY 247)

\begin{tabular}{ccccc}
$2018 / 241$ & 2347 & 1624 & 2326 & 322 \\
$2018 / 242$ & 1397 & 955 & 1378 & 189 \\
$2018 / 243$ & 937 & 626 & 911 & 123 \\
$2018 / 244$ & 578 & 370 & 549 & 72 \\
$2018 / 245$ & 384 & 226 & 347 & 44 \\
$2018 / 246$ & 190 & 87 & 146 & 17 \\
$2018 / 247$ & 86.8 & 4.1 & 28.3 & 3.9 \\
For observations on 2019/08/23(DOY 235) & & \\
$2019 / 228$ & 349 & 233 & 343 & 64 \\
$2019 / 229$ & 120 & 80 & 114 & 22 \\
$2019 / 230$ & 26 & 17 & 21 & 3.9 \\
$2019 / 231$ & 13.9 & 8.3 & 10.2 & 1.8 \\
$2019 / 232$ & 17.3 & 10.3 & 15.2 & 2.7 \\
$2019 / 233$ & 13.2 & 7.5 & 11.8 & 1.9 \\
$2019 / 234$ & 4.6 & 2.7 & 4.2 & 0.8 \\
For observations on 2019/08/24(DOY 236) & & \\
$2019 / 229$ & 159 & 111 & 152 & 40 \\
$2019 / 230$ & 50 & 34 & 44 & 12 \\
$2019 / 231$ & 34.1 & 22.7 & 29.2 & 7.8 \\
$2019 / 232$ & 37.6 & 25.1 & 34.2 & 8.9 \\
$2019 / 233$ & 31.8 & 21.0 & 29.1 & 7.4 \\
$2019 / 234$ & 20.0 & 13.1 & 18.5 & 4.6 \\
$2019 / 235$ & 11.9 & 7.4 & 11.0 & 2.5 \\
\hline
\end{tabular}

pulse on the array, useful to determine its effective OCS (Fig. 4), can be obtained from the telemetered LRO attitude information, and corresponds in these plots to the angle from $-90^{\circ}$ elevation (for which the line-of-sight to Grasse would be directly along the array normal).

\section{Subsequent successful session in August 2019}

Other attempts were made following the September 2018 success, but were either canceled due to bad weather or postponed due to station equipment maintenance and upgrades. During that time, the active slewing approach was developed and tested.

Mid-late August 2019 was very favorable from a geometry perspective, and a number of slews were commanded over 7 days (one to two a day). The first two nights did not provide LRO returns despite good seeing of the Apollo surface retro-reflectors. The next few nights were clouded out, but the weather cleared for the last two nights. Two passes were successful on August 23rd between 02:34 and 02:46 UTC and on August 24th between 1:56 and 2:14 UTC. Figure 8c, $d$ shows the path of the Earth in the LRO spacecraft frame during these two periods.

\section{Analysis}

We compared the ranging measurements to predicted values computed using the LRO trajectory, with the SPICE toolkit (Acton 1996). We used high-precision Earth orientation and the station meteorological data to compute range corrections. The residuals (observed minus computed) of the two-way light times show systematic trends when using either predicted or reconstructed kernels, due to orbital errors, with biases on the order of a few nanoseconds and rates of $0.25-1.50 \mathrm{~ns} /$ $\mathrm{min}$. We removed these trends with a simple degree-3 polynomial fit. The detrended residuals are shown in Fig. 9. They show the intrinsic noise level over each of the four passes. The RMS values are $\sim 166 \pm 35$ ps, which corresponds to $2.50 \pm 0.54 \mathrm{~cm}$ in one-way range.

\section{Discussion and perspectives}

The motivation for placing the LRA in lunar orbit onboard LRO was to provide a known pristine target for LLR systems to ascertain any degradation of the LRAs left on the surface. Independent combined analysis of echo return rates for both 532- and 1064-nm pulses at the Grasse station did not show what would be expected from the deposition of a fine layer or partial layer of dust on the surface corner cubes (Courde et al. 2017b).

Immediately surrounding the LRO ranging experimental periods, the Grasse station also ranged to these surface retro-reflectors. This significantly reduced the possible sources of variation in link margin due to temporal variations (less than few hours) in atmospheric conditions, Moon elevation, etc. The return rate for each pass was computed from the number of returned echos and the pass duration. Table 3 shows a summary of the relevant passes for the successful observations in 2018 and 2019.

In Table 3, the median value of the average return rate measured on A11 and A14 surface LRA (both are identical) was $5.37 \%$. As a matter of comparison, we computed the statistics of the average return rate per normal point from these two surface LRAs from Grasse LLR station over the year 2019 in Fig. 10: only 2\% of the normal points reach this return rate or higher. This shows that conditions matching the successful two-way ranging sessions to LRO (e.g., Moon elevation, weather, dark background) are rare in the sample from Grasse LLR observations.

Here, we list all the known parameters that may affect the efficiency of the return from the LRA. First, the 

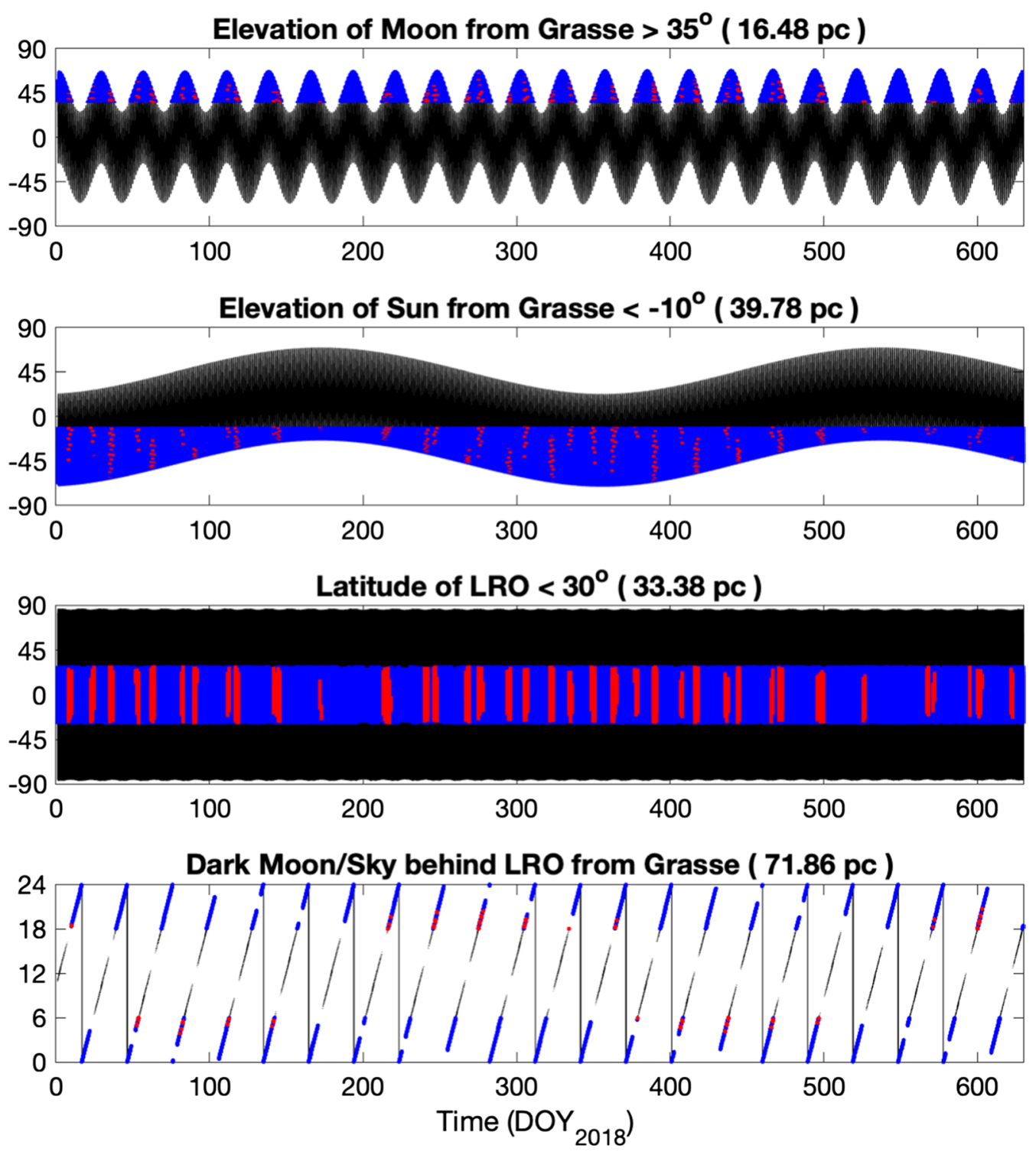

Fig. 7 Evolution of key geometry parameters. These are shown for the LRO-Grasse opportunities, between January 1, 2018 and September 22 , 2019. The black lines give the complete time series of these parameters, and the blue lines the segments where the constraint on that parameter is satisfied. Their total duration relative to the time span is given in parenthesis as a percentage. The red lines indicate the periods where all four constraints are satisfied and thus when passive ranging may be attempted

incidence angle can strongly affect the return rate (see Fig. 4 for the optical cross-section of LRO's LRA) and one must determine the incidence angle at LRO during the pass to take this into account. For the surface LRA, the lunar libration can be responsible for a variation of the incidence angle with a maximum amplitude of 8 degrees, which can reduce the return rate by up to $60 \%$ over the lunar cycle. Then, solar radiation effects on the efficiency of the surface LRA have been evaluated, and depending on the angle of the Sun direction to the normal, the surface LRA can see a reduction in efficiency up to $45 \%$ compared to night time conditions. During the passes considered here, all retro-reflectors were in the dark, and the effect of the Sun was therefore irrelevant, but the libration of the Moon had to be taken into account. For instance, during 2019 passes, the libration of the Moon was around 6.75 degrees; according to the OCS of the surface LRA (Alley et al. 1969), this reduces their return efficiency by $50 \%$. During the 2018 passes, the libration was 4.5 degrees, reducing their efficiency by $40 \%$. The Earth atmosphere is also a factor that can affect the return rate measured at the LLR station. 

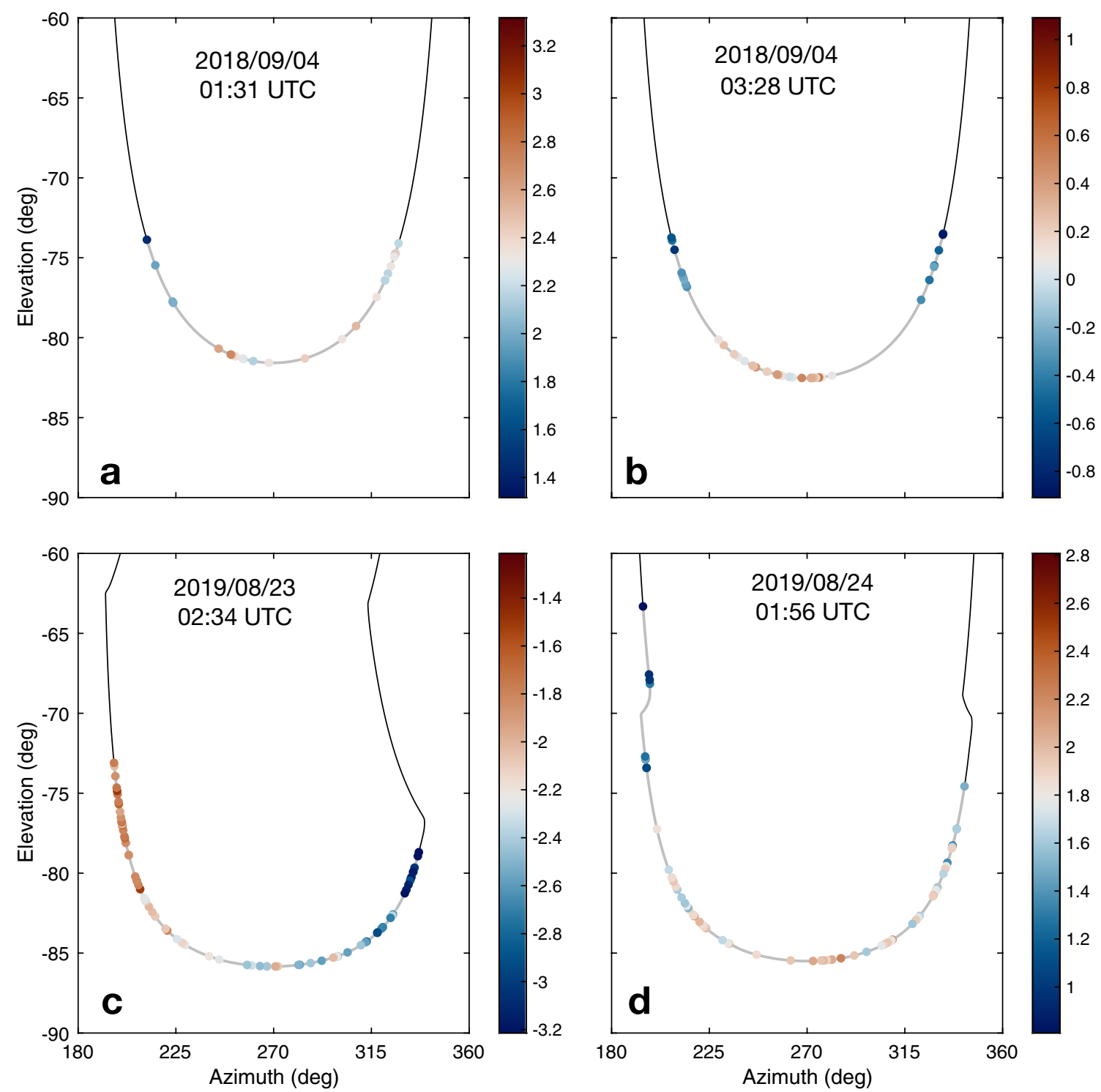

Fig. 8 Path of the Grasse station as seen from LRO. Each figure is for the four successful passes. Shown in the LRO spacecraft bus frame, an elevation of $-90^{\circ}$ represents the anti-nadir direction which is also the retro-reflector array normal. Elevations below $\approx-70^{\circ}$ are within the LRA FOV. The points show the individual returns, colored by the residual (observed minus computed, in ns) with respect to the LRO trajectory ( $\pm 1 \mathrm{~ns}$ around the median)

Although the surface LRA were ranged to immediately before and after the LRO passes, the atmospheric conditions can change over relatively short time periods. Humidity at the level of the LLR station can vary rapidly, as observed between the two LRO passes in 2018 (see Table 3). However, the return rate from LRO did not increase as much as on the surface LRA. The turbulence depends on the meteorological conditions and for example, for the 2018 passes, the median seeing value was about $2^{\prime \prime}$ during the night, but the standard deviation of the seeing measured by the seeing monitor between 1:20 and 2:18 UTC is around $0.46^{\prime \prime}$. Such a variability, often observed with larger seeing values, can affect the instantaneous return rate at a timescale of minutes. Before comparing the return rate between retro-reflectors, even within a short time period, the stability of the atmospheric parameters must be verified. Finally, all the passes were acquired with a dark background, i.e., without direct visual confirmation of the pointing from the lunar surface features (e.g., around the Apollo landing sites) to mitigate possible pointing errors from the operators. 


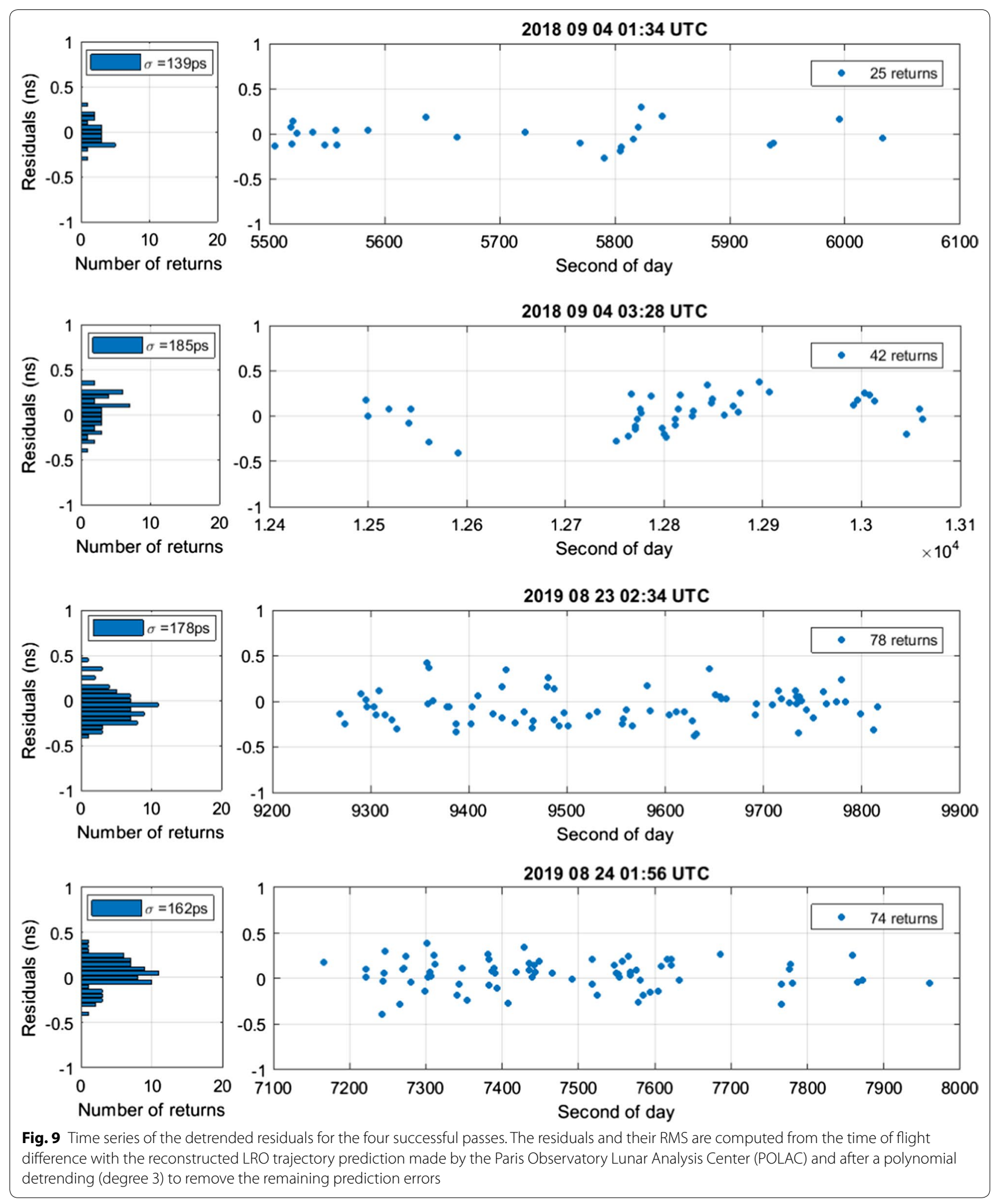


Table 3 Statistics of the two-way LLR passes obtained by Grasse during and immediately surrounding the LRO ranging experimental periods

\begin{tabular}{|c|c|c|c|c|c|c|}
\hline Time (UTC) & Target & $\Delta t(\min )$ & Number echos & Range (km) & Return rate (\%) & Hum. (\%) \\
\hline \multicolumn{7}{|c|}{ Date: 2018-09-04 } \\
\hline 01:31:00 & LRO & 8.20 & 25 & 366,726 & 0.51 & 69 \\
\hline $01: 51: 45$ & A11 & 14.55 & 405 & 366,641 & 4.64 & 73 \\
\hline 02:05:09 & A14 & 11.23 & 506 & 366,241 & 7.51 & 77 \\
\hline 02:44:04 & A11 & 11.33 & 365 & 365,659 & 5.37 & 86 \\
\hline $02: 50: 26$ & A14 & 3.78 & 155 & 365,408 & 6.83 & 89 \\
\hline 03:28:00 & LRO & 9.40 & 43 & 364,568 & 0.76 & 92 \\
\hline 03:45:49 & A11 & 10.22 & 786 & 364,666 & 12.82 & 92 \\
\hline 03:58:33 & A14 & 12.75 & 1002 & 364,346 & 13.09 & 92 \\
\hline \multicolumn{7}{|c|}{ Date: 2019-08-23 } \\
\hline 01:52:22 & $\mathrm{A} 11$ & 10.22 & 249 & 386,389 & 4.06 & 66 \\
\hline 02:34:00 & LRO & 9.20 & 76 & 385,441 & 1.38 & 67 \\
\hline $03: 40: 23$ & $\mathrm{~A} 11$ & 10.98 & 113 & 384,881 & 1.71 & 62 \\
\hline 03:51:03 & A14 & 10.30 & 304 & 384,587 & 4.92 & 62 \\
\hline \multicolumn{7}{|c|}{ Date: 2019-08-24 } \\
\hline 01:52:59 & $\mathrm{A} 11$ & 3.88 & 45 & 381,402 & 1.93 & 72 \\
\hline 01:56:00 & LRO & 13.80 & 76 & 380,942 & 0.92 & 71 \\
\hline $02: 39: 33$ & A11 & 10.37 & 35 & 380,525 & 0.56 & 76 \\
\hline
\end{tabular}

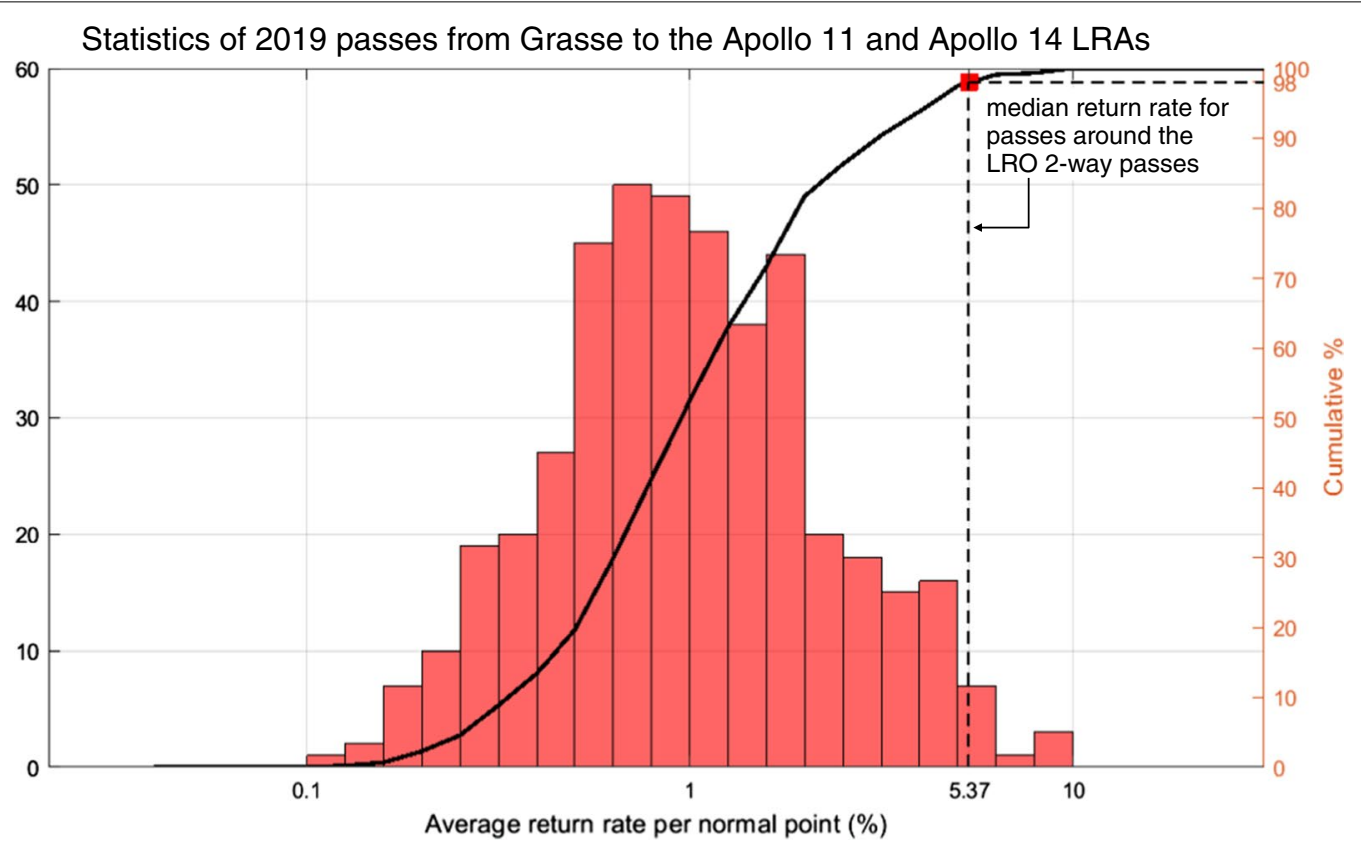

Fig. 10 Average return rate of LLR to surface LRAs. The distribution shows the average return rate per normal point from A11 and A14 LRA from Grasse LLR station for 2019

This first analysis shows the difficulty of ranging the LRO's LRA. The successful passes were realized during some of the best statistically observed conditions for LLR ranging experiments. The amount of acquired data, sometimes while atmospheric conditions were not so stable, is not yet sufficient to firmly conclude on the possible degradation of the surface LRA. To do so, the link budget must be improved. The Grasse LLR station is currently implementing a new laser solution with a nanosecond-pulse Nd:YAG laser, to provide up to $1 \mathrm{~J}$ of 
energy per pulse (vs. $0.3 \mathrm{~J}$ currently). The range precision may be degraded but this experiment is primarily focused on the comparison of the LRA efficiency. The current observations have given us good knowledge of the conditions to perform successful two-way laser ranging to LRO's LRA. This will help us prepare for a number of new attempts. As we accumulate returns in different geometry and configurations, but mostly improve the statistics with more passes, we will be able to perform a detailed quantitative study to ascertain the possible degradation of the surface LRA due to dust deposition.

The participation of other stations to this experiment would provide additional geometry and thus increase the number of ranging opportunities. Passive opportunities would for instance occur in different windows or seasons with southern hemisphere laser stations. This would require the participation of LRO of course and would constitute a very challenging experiment, especially for stations working at $532 \mathrm{~nm}$. To range to a small array like that of LRO, the station would need to be capable of routine LLR observations under many observation conditions. It would however provide a first potential demonstration of direct time transfer of distant ground stations by laser links to a lunar orbiter.

\section{Conclusion}

We reported the first successful two-way laser ranging to a spacecraft at lunar distance. Several of these challenging observations were made by the Grasse station to the retro-reflector array onboard LRO. Despite the small size of the LRO LRA, the laser echos could be clearly identified and have an intrinsic range precision of $<3 \mathrm{~cm}$. That precision level would be valuable for LLR, particularly at new lunar sites near the poles or limbs (Merkowitz 2010). Continued observations from Grasse to LRO are needed in the future to help quantitatively assess link margin differences and thus possible degradation due to dust deposition of the Apollo and Lunokhod LRAs.

\footnotetext{
Abbreviations

A11: Apollo 11; A14: Apollo 14; APOLLO: Apache point observatory lunar laser-ranging operation; CC: Corner cube; CCD: Charge-coupled device; CDDIS: Crustal dynamics data information system; CMOS: Complementary metal-oxide-semiconductor; DOY: Day of year; DSN: Deep space network; FOV: Field of view; G-DIMM: Generalized differential IMage Monitor; GRAIL: Gravity recovery and interior laboratory; GSFC: Goddard Space Flight Center; HGA: High-gain antenna; IERS: International Earth Rotation Service; ILRS: International Laser Ranging Service; LLR: Lunar Laser Ranging; LOLA: Lunar Orbiter Laser Altimeter; LRA: Laser retro-reflector array; LRO: Lunar reconnaissance orbiter; LRT: Laser Ranging Telescope; OCS: Optical cross-section; POLAC: Paris Observatory Lunar Analysis Center; RMS: Root mean square; RR: Retro-reflector; SPAD: Single-photon avalanche diode; TIR: Total internal reflection; TPF: Topocentric prediction format; USN: Universal Space Network; UTC: Coordinated Universal Time.
}

\section{Acknowledgements}

We thank the LRO Operations team and the LRO Project for their support of this experiment. We also thank Mr. E. Aaron of KBRWyle for the fabrication of the LRA on LRO, and Mr. S. Wake for the optical testing of the LRA at GSFC.

\section{Authors' contributions}

$D S, M Z, X S$ and GN designed the LRO experiment and led the build of the LRA. $X S$ and DC obtained experimental optical measurements of the LRA. PE, JMT, CC, JC, FL, DS, XS and EM set up the experiment to Grasse. JMT, CC, JC, MA, HM and NM defined the station operation plan and conducted the observation attempts. EM and DM identified the opportunities and planned them with the $L R O$ team. MB and DM supported the design of the $L R O$ slews required to bring the LRA in alignment. SB, TC and AB prepared station-specific predictions for the telescope. EM provided the LRO orbit predictions for the two-way tests and reconstructed the LRO orbit for analysis. CC, JC, SB, EM and VV analyzed the returned pulse data. EM, XS, DC, CC and JC prepared the initial manuscript. All authors provided feedback. All authors read and approved the final manuscript.

\section{Funding}

This work was supported by the NASA LRO Project, the Centre National de la Recherche Scientifique-Institut National des Sciences de I'Univers (CNRSINSU), and the Centre National d'Etudes Spatiales (CNES). This work was also supported by the LABEX Cluster of Excellence FIRST-TF (ANR-10-LABX-48-01), within the Program "Investissements d'Avenir" operated by the French National Research Agency (ANR).

\section{Availability of data and materials}

The datasets used and/or analyzed during the current study are available from the corresponding author upon request.

\section{Competing interests}

The authors declare no competing interests.

\section{Author details}

${ }^{1}$ NASA Goddard Space Flight Center (GSFC), Greenbelt, MD, USA. ${ }^{2}$ Université Côte d'Azur, Observatoire de la Côte d'Azur (OCA), CNRS, IRD, Géoazur, Nice, France. ${ }^{3}$ Hexagon US Federal, Chantilly, VA, USA. ${ }^{4}$ Observatoire de ParisMeudon, Paris, France. ${ }^{5}$ CRESST, University of Maryland, Baltimore County, Baltimore, MD, USA. ${ }^{6}$ Università di Bologna, Bologna, Italy. ${ }^{7}$ Géosciences Environnement Toulouse, Observatoire Midi-Pyrénées, Toulouse, France. ${ }^{8}$ Massachusetts Institute of Technology (MIT), Cambridge, MA, USA.

Received: 30 April 2020 Accepted: 30 July 2020

Published online: 06 August 2020

\section{References}

Acton CH (1996) Ancillary data services of NASA's Navigation and Ancillary Information Facility. Planet Space Sci 44(1):65-70. https://doi. org/10.1016/0032-0633(95)00107-7

Alley CO, Bender L, Chang RF, Currie DG, Dicke RH, Faller JE, Kaula WM, MacDonald GJF, Mulholland JD, Plotkin HH, Poultney SK, Wilkinson DT, Winer I, Carrion W, Johnson T, Spadin P, Robinson L, Wampler EJ, Wieber D, Silverberg E, Steggerda C, Mullendore J, Rayner J, Williams W, Warner B, Richardson H, Bopp B (1969) Apollo 11 Preliminary Science Report: 7 Laser Ranging Retroreflector. Technical report, NASA

Aristidi E, Ziad A, Chabé J, Fantéi-Caujolle Y, Renaud C, Giordano C (2019) A generalized differential image motion monitor. Mon Not R Astron Soc 486(1):915-925. https://doi.org/10.1093/mnras/stz854

Chabé J, Courde C, Torre J-M, Bouquillon S, Bourgoin A, Aimar M, Albanèse D, Chauvineau B, Mariey H, Martinot-Lagarde G, Maurice N, Phung D-H, Samain E, Viot H (2020) Recent Progress in Lunar Laser Ranging at Grasse Laser Ranging Station. Earth Space Sci 7(3):000785. https://doi. org/10.1029/2019EA000785

Courde C, Torre JM, Samain E, Martinot-Lagarde G, Aimar M, Albanese D, Maurice N, Mariey H, Viot H, Exertier P, Fienga A, Viswanathan V. Satellite and lunar laser ranging in infrared. In: Proc. SPIE. Society of Photo-Optical Instrumentation Engineers (SPIE) Conference Series, vol. 10229, p. 102290 (2017). https://doi.org/10.1117/12.2270573 
Courde C, Torre JM, Samain E, Martinot-Lagarde G, Aimar M, Albanese D, Exertier P, Fienga A, Mariey H, Metris G, Viot H, Viswanathan V (2017) Lunar laser ranging in infrared at the Grasse laser station. Astron Astrophys 602:90. https://doi.org/10.1051/0004-6361/201628590

Currie D, Dell'Agnello S, Delle Monache G (2011) A lunar laser ranging retroreflector array for the 21st century. Acta Astronaut 68(7):667-680. https:// doi.org/10.1016/j.actaastro.2010.09.001

Degnan JJ (2013) Millimeter accuracy satellite laser ranging: a review. American Geophysical Union, Washington, pp 133-162. https://doi. org/10.1029/GD025p0133

Dell'Agnello S, Boni A, Cantone C, Ciocci E, Martini M, Patrizi G, Tibuzzi M, Monache GD, Vittori R, Bianco G, Currie D, Intaglietta N, Salvatori L, Lops C, Contessa S, Porcelli L, Mondaini C, Tuscano P, Maiello M (2018) Next-generation laser retroreflectors for GNSS, solar system exploration, geodesy, gravitational physics and earth observation. In: Sodnik Z, Cugny B, Karafolas N. (eds.) International Conference on Space Optics-ICSO 2014, vol. 10563, pp. 347-355. SPIE, Tenerife, Canary Islands, Spain (2018). https://doi.org/10.1117/12.2304232. International Society for Optics and Photonics

Exertier P, Samain E, Bonnefond P, Guillemot P (2010) Status of the T2L2/Jason2 Experiment. Adv Space Res 46(12):1559-1565. https://doi.org/10.1016/j. asr.2010.06.028

Exertier P, Samain E, Courde C, Martin N, Torre J, Oneto J, Geoazur, ML, Guillemot P, Léon, S.: T2L2: Five years in space. In: 2013 Joint European Frequency and Time Forum International Frequency Control Symposium (EFTF/IFC), pp 632-635 (2013)

He Y, Liu Q, Duan H-Z, He J-J, Jiang Y-Z, Yeh H-C (2018) Manufacture of a hollow corner cube retroreflector for next generation of lunar laser ranging. Res Astron Astrophys 18(11):136. https://doi. org/10.1088/1674-4527/18/11/136

Mao D, McGarry JF, Mazarico E, Neumann GA, Sun X, Torrence MH, Zagwodzki TW, Rowlands DD, Hoffman ED, Horvath JE, Golder JE, Barker MK, Smith DE, Zuber MT (2017) The laser ranging experiment of the Lunar Reconnaissance Orbiter: Five years of operations and data analysis. Icarus 283:55-69. https://doi.org/10.1016/j.icarus.2016.07.003

Mazarico E, Neumann GA, Barker MK, Goossens S, Smith DE, Zuber MT (2018) Orbit determination of the Lunar Reconnaissance Orbiter: Status after seven years. Planet Space Sci 162:2-19. https://doi.org/10.1016/j. pss.2017.10.004

Merkowitz SM (2010) Tests of Gravity Using Lunar Laser Ranging. Living Rev Relativ 13(1):7. https://doi.org/10.12942//rr-2010-7

Minott PO (1974) Measurement of the lidar cross sections of cube corner arrays for laser ranging of satellites. Technical report. https://ntrs.nasa. gov/search.jsp?R=19750012635

Müller J, Murphy TW, Schreiber U, Shelus PJ, Torre J-M, Williams JG, Boggs DH, Bouquillon S, Bourgoin A, Hofmann F (2019) Lunar Laser Ranging: a tool for general relativity, lunar geophysics and Earth science. J Geodesy. https ://doi.org/10.1007/s00190-019-01296-0
Murphy TW (2013) Lunar laser ranging: the millimeter challenge. Rep Prog Phys 76(7):076901. https://doi.org/10.1088/0034-4885/76/7/076901

Murphy JTW, Adelberger EG, Battat JBR, Carey LN, Hoyle CD, LeBlanc P, Michelsen EL, Nordtvedt K, Orin AE, Strasburg JD, Stubbs CW, Swanson HE, Williams E (2008) The Apache Point Observatory Lunar Laser-ranging Operation: Instrument Description and First Detections. Publ Astron Soc Pac 120(863):20. https://doi.org/10.1086/526428

Murphy TW, Adelberger EG, Battat JBR, Hoyle CD, McMillan RJ, Michelsen EL, Samad RL, Stubbs CW, Swanson HE (2010) Long-term degradation of optical devices on the Moon. Icarus 208(1):31-35. https://doi. org/10.1016/j.icarus.2010.02.015

Murphy TW, McMillan RJ, Johnson NH, Goodrow SD (2014) Lunar eclipse observations reveal anomalous thermal performance of Apollo reflectors. Icarus 231:183-192. https://doi.org/10.1016/j.icarus.2013.12.006

Noll CE, Ricklefs R, Horvath, J, Mueller H, Schwatke C, Torrence M. (2018) Information resources supporting scientific research for the international laser ranging service. J Geod. https://doi.org/10.1007/s00190-018-1207-2

Pearlman MR, Noll CE, Pavlis EC, Lemoine FG, Combrink L, Degnan JJ, Kirchner G, Schreiber U (2019) The ILRS: approaching 20 years and planning for the future. J Geodesy. https://doi.org/10.1007/s00190-019-01241-1

Smith DE, Zuber MT, Jackson GB, Cavanaugh JF, Neumann GA, Riris H, Sun X, Zellar RS, Coltharp C, Connelly J, Katz RB, Kleyner I, Liiva P, Matuszeski A, Mazarico EM, McGarry JF, Novo-Gradac A-M, Ott MN, Peters C, RamosIzquierdo LA, Ramsey L, Rowlands DD, Schmidt S, Scott VS, Shaw GB, Smith JC, Swinski J-P, Torrence MH, Unger G, Yu AW, Zagwodzki TW (2009) The Lunar Orbiter Laser Altimeter Investigation on the Lunar Reconnaissance Orbiter Mission. Space Sci Rev 150(1-4):209-241. https://doi. org/10.1007/s11214-009-9512-y

Sun X, Smith DE, Hoffman ED, Wake SW, Cremons DR, Mazarico E, Lauenstein J-M, Zuber MT, Aaron EC (2019) Small and lightweight laser retroreflector arrays for lunar landers. Appl Opt 58(33):9259-9266. https://doi. org/10.1364/AO.58.009259

Zuber MT, Smith DE, Zellar RS, Neumann GA, Sun X, Katz RB, Kleyner I, Matuszeski A, McGarry JF, Ott MN, Ramos-Izquierdo LA, Rowland DD, Torrence MH, Zagwodzki TW (2010) The Lunar Reconnaissance Orbiter Laser Ranging Investigation. Space Sci Rev 150(1-4):63-80. https://doi.org/10.1007/ s11214-009-9511-z

Zuber MT, Smith DE, Watkins MM, Asmar SW, Konopliv AS, Lemoine FG, Melosh HJ, Neumann GA, Phillips RJ, Solomon SC, Wieczorek MA, Williams JG, Goossens SJ, Kruizinga G, Mazarico E, Park RS, Yuan D-N (2013) Gravity Field of the Moon from the Gravity Recovery and Interior Laboratory (GRAIL) Mission. Science 339(6120):668-671. https://doi.org/10.1126/ science. 1231507

\section{Publisher's Note}

Springer Nature remains neutral with regard to jurisdictional claims in published maps and institutional affiliations.

\section{Submit your manuscript to a SpringerOpen ${ }^{\mathcal{O}}$ journal and benefit from:}

- Convenient online submission

- Rigorous peer review

- Open access: articles freely available online

- High visibility within the field

- Retaining the copyright to your article

Submit your next manuscript at $\boldsymbol{\Delta}$ springeropen.com 